\title{
Preparation of Amides via Intermolecular Dehydrogenative Coupling of Alcohols with Amines
}

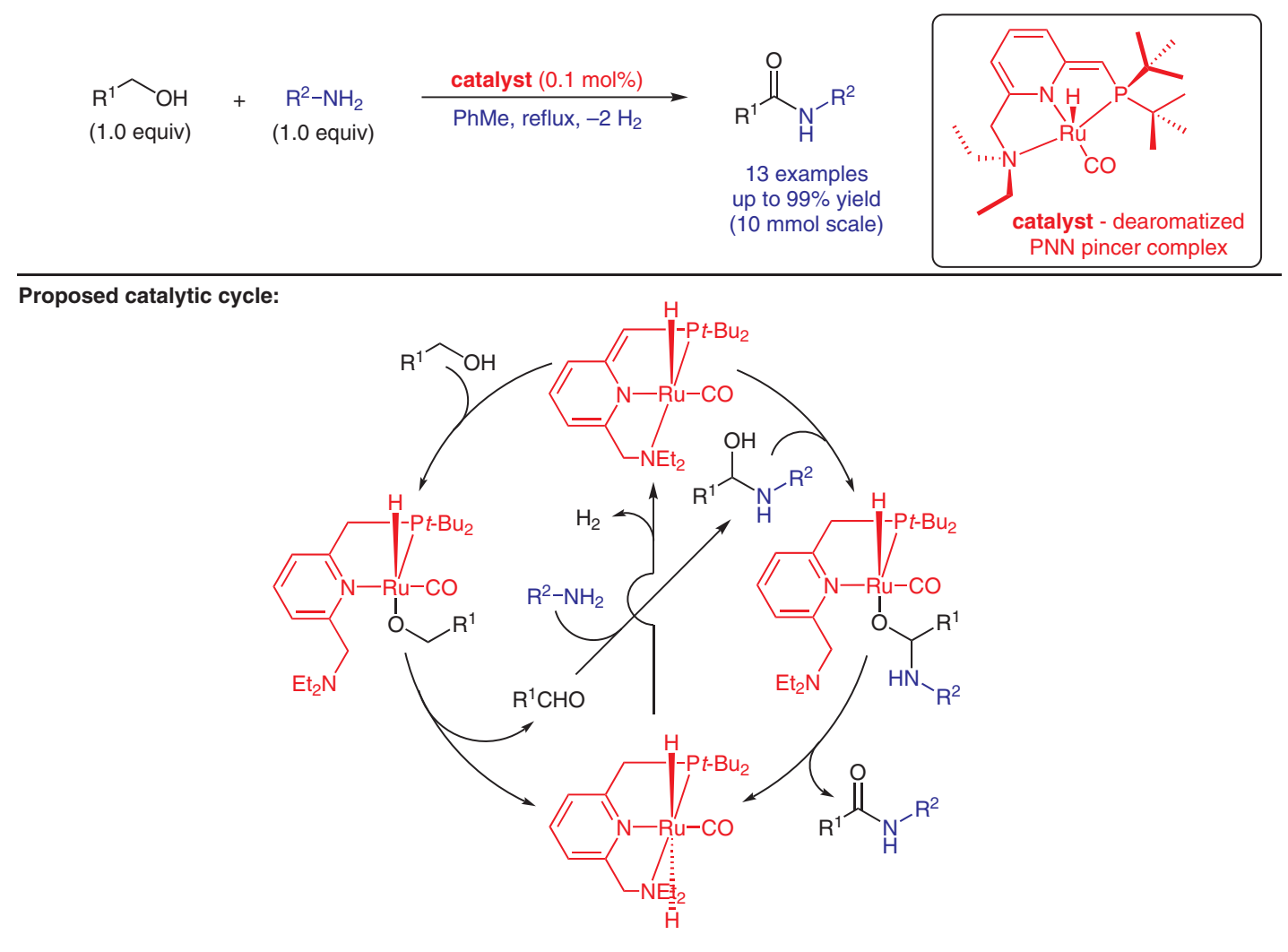

Selected examples:<smiles>CCCCCC(=O)NCc1ccccc1</smiles>

$96 \%$ yield<smiles>COCC(=O)NCc1ccccc1</smiles>

$99 \%$ yield<smiles>CCC(C)C(=O)NCc1ccccc1</smiles>

$70 \%$ yield<smiles>CCCCCC(=O)NC(C)CCCCC</smiles>

$72 \%$ yield<smiles>COCC(=O)NC1CCCCC1</smiles>

$99 \%$ yield<smiles>COCC(=O)NCCNC(=O)COC</smiles>

$99 \%$ yield
Significance: Miltstein and co-workers reported a direct catalytic approach for the preparation of amides from alcohols and amines. The reaction proceeds under mild conditions, with low catalyst loading ( $0.1 \mathrm{~mol} \%)$, and affords the products in excellent yields. It offers an attractive, atom-economical alternative to conventional acylation of amines.
Comment: The reaction is sensitive to steric hindrance, as the presence of $\alpha$-substituents on either the alcohol or amine led to reduced yields of the desired product, while secondary amines showed no reactivity. Notably, unreacted starting material alcohol is converted into its corresponding ester product.

Review: C. Gunanathan, D. Milstein Science 2013, 341, 1229712.

\section{Key words}

ruthenium catalysis

dehydrogenative coupling

pincer complex

Milstein catalyst

\section{Synfact $\dot{\vec{m}}$} Classic 